\title{
Predicted Values for Lung Diffusing Capacity in Healthy Children
}

\author{
Samya Z. Nasr, MD, Patricia Amato, RRT, RPFT, and Robert W. Wilmott, BSC, MD, MRCP

\begin{abstract}
Summary. Lung diffusing capacity was measured in 92 healthy Caucasian children ( 52 boys and 40 girls), ranging in age from 6 to 17 years, using the single breath carbon monoxide technique $\left(D L_{C O}\right)$. Multiple regression equations were developed to predict the $D L_{C o}$ value. Standing height, gender, weight, and age were significant factors in the prediction of $D L_{c o}$. Sitting height was not a significant covariate when standing height was in the model, but it could replace standing height in the equation. Equations are presented for the calculation of predicted $\mathrm{DL}_{\mathrm{CO}}$ in children based on standing or sitting height, age, sex, and weight. Pediatr Pulmonol. 1991; 10:267-272.
\end{abstract}

Key words: Single breath $\mathrm{DL}_{\text {co; }}$ gas chromatography; stepwise multiple regression analysis; $\mathrm{DL}_{\text {co }}$ TLC (Krogh factor).

\section{INTRODUCTION}

The single breath carbon monoxide diffusing capacity $\left(\mathrm{DL}_{\mathrm{CO}}\right)$ is one of the most widely used tests of pulmonary gas exchange in clinical medicine and in respiratory epidemiology. It has been especially valuable in the early detection and quantitation of interstitial lung disease.

Predicted values of $\mathrm{DL}_{\mathrm{CO}}$ for children ${ }^{1,2,3,4,5,6,7}$ have been based on small numbers of subjects or different methods than the gas chromatographic procedure that we employed. This method can be applied to subjects with a smaller vital capacity than $1,000 \mathrm{~mL}$ which is required with most other techniques. The study was undertaken to determine the predicted values for lung diffusing capacity in healthy children.

\section{MATERIALS AND METHODS}

The original study population consisted of 104 healthy caucasian children, 6-17 years of age, (57 males and 47 females). Subjects were recruited from the relatives of employees of Children's Hospital of Michigan, which was a convenience sample. Fully informed consent was obtained from the parents, then medical histories were taken by interview and the children were examined. The study was approved by the Human Subjects Committee of Children's Hospital of Michigan. All subjects denied any respiratory problems, and none were receiving medical therapy. Two subjects reported occasional cigarette smoking, but neither had smoked 16-18 hours prior to the test, thus the results could be regarded as unaffected. ${ }^{8}$ Measurements of standing height and sitting height were obtained using a Harpenden stadiometer.
Weight was measured on a scale, and chronological age was recorded.

Pulmonary function measurements were made on the Medical Graphics Corporation CAD/NET ${ }^{\mathrm{TM}}$ Pulmonary Function Testing System 1070 and Body Plethysmography System 1085. We used software version 3.7a (Medical Graphics Corporation, St. Paul, Minnesota). A gas chromatograph is part of the 1070 system for measuring gas concentrations. The gas chromatograph is significantly more reliable for small sample sizes than alternative analyzers. It is specific for the gas being analyzed and this obviates the need to remove moisture, carbon dioxide, and alcohol from the sample. It also eliminates the volume correction necessary with some methods. The pneumotachographs were calibrated daily and used according to the manufacturer's specifications.

All subjects were seated during the tests. Spirometry was measured on the 1070 and lung volumes on the 1085 system. Results were calculated and reported according to ATS standards. ${ }^{9,10}$ The spirometry and lung volume

From Wayne State University, School of Medicine, Department of Pediatrics, Division of Pulmonary Medicine, Children's Hospital of Michigan, Detroit, Michigan.

S.Z.N. is currently a Pulmonary Fellow, Department of Pediatrics, Division of Pulmonary Medicine, University of Michigan, Ann Arbor, Michigan.

Address correspondence and reprint requests to: Dr. R.W. Wilmott, Division of Pulmonary Medicine, Children's Hospital Medical Center, Elland and Bethesda Avenues, Cincinnati, OH 45229-2899.

Received February 21, 1990; (revision) accepted for publication January 22, 1991. 
TABLE 1-Mean Values \pm Standard Deviations and (Range) of Vital Statistics in the Study Subjects

\begin{tabular}{lccccc}
\hline & & & Standing & Sitting & \\
& $\mathrm{n}$ & Age (years) & height $(\mathrm{cm})$ & height (cm) & Weight (kg) \\
\hline Boys & 52 & $11.2 \pm 2.9$ & $145.6 \pm 15.7$ & $76.3 \pm 7.3$ & $41.3 \pm 15.2$ \\
& & $(6.5-17.3)$ & $(121.5-180.0)$ & $(62.0-93.5)$ & $(22.0-78.9)$ \\
Girls & 40 & $11.3 \pm 3.1$ & $145.2 \pm 16.6$ & $76.5 \pm 8.1$ & $43.3 \pm 18.9$ \\
& & $(6.6-17.3)$ & $(118.3-171.5)$ & $(64.5-91.7)$ & $(21.0-99.9)$ \\
\hline
\end{tabular}

measurements for all subjects were compared to the standards of Weng and Levison, ${ }^{11}$ Knudson, ${ }^{12}$ and Cotes. $^{2}$

The $\mathrm{DL}_{\mathrm{CO}}$ gas mixture was $0.5 \%$ neon, $20.97 \%$ oxygen, $0.3 \% \mathrm{CO}$, and the remainder was nitrogen. Helium was used as the carrier gas, to transport the sample through the gas chromatograph column of diatomaceous earth which separated the constituent gases by molecular size.

The single breath $\mathrm{DL}_{\mathrm{CO}}$ test was performed according to the method of Krogh, ${ }^{13}$ as modified by Forster et al. ${ }^{14}$ and Ogilvie, et al. ${ }^{15}$ The seated subject was instructed to breathe normally. Once breathing was normal, the subject was instructed to inhale to total lung capacity (TLC), exhale fully to residual volume (RV), pause briefly, then upon command, inhale quickly to TLC. This breath was held for 9-11 seconds during which time the patient was instructed to relax against the closed valve to avoid Valsalva maneuvers.

The DL $_{\mathrm{CO}}$ measurement was considered acceptable if breath holding time was between 9 and 11 seconds; inspiratory time $<2$ seconds, and sample collection time $<3$ seconds. The procedure was repeated for a maximum of 4 trials and the acceptable trials were averaged. If the subject had only one acceptable maneuver, that value was analyzed. There was a minimum wait of 5 minutes between tests to allow elimination of the test gas from the lungs.

Data were recorded on an IBM PS2 System 80 computer using dBase III plus software (Ashton-Tate Corporation, Torrance, California) and analyzed with the program SPSS/PC+ (SPSS Inc., Chicago, Illinois). Copies of the database on floppy disks are available by contacting the corresponding author, (Robert W. Wilmott, M.D.). Statistical analysis included linear regression by the least squares method and stepwise multiple regression analysis using the following independent variables: gender, standing height, sitting height, weight, and TLC. $\mathrm{DL}_{\mathrm{CO}}$ and the $\mathrm{DL}_{\mathrm{CO}}$-to-TLC ratio (Krogh factor) were analyzed as independent variables. A $P$ value less than 0.05 was considered statistically significant.

\section{RESULTS}

The characteristics of the study population are summarized in Table 1. Twleve of the 104 children ( 5 boys and 7 girls) who were tested could not perform the DL $\mathrm{CO}$ maneuver satisfactorily. They were all less than 8 years of age and represented $50 \%$ of the sample in the children aged 6-8 years.

Ninety of the remaining 92 children were between the 5 th and 95 th height centiles ${ }^{16}$ for their ages. One boy and one girl fell just above the 95 th centile. Eighty-five of the 92 children plotted between the 5th and the 95th weight centiles for age. ${ }^{16}$ Three girls and four boys were above the 95th centile. These data suggest that we selected a representative sample of normal children. This was also checked by plotting forced vital capacity against height in boys and girls (Fig. 1). Thirty-nine of 40 girls and 49 of 52 boys fell inside the $95 \%$ confidence intervals of the normal data reported by Cotes. ${ }^{2}$ Thus, $95.6 \%$ of subjects lay within the $95 \%$ confidence intervals, confirming that this was a representative sample of normal children.

The value of $\mathrm{DL}_{\mathrm{CO}}$ correlated with standing height, sitting height, age, and TLC, in simple linear regression (Table 2). In general, there was no effect of gender on these correlation coefficients, when values for boys and girls were compared. However, the Krogh factor ( $\mathrm{DL}_{\mathrm{CO}}$ TLC) did correlate negatively with TLC $(\mathrm{R}=-0.4223$, $P<0.01)$ in girls but not in boys $(\mathrm{R}=-0.2618, P=$ $\mathrm{NS}$ ); it did not correlate significantly with sitting or standing height. Figure 2 illustrates the relationship between $\mathrm{DL}_{\mathrm{CO}}$ and standing height in boys and girls.

By stepwise multiple regression analysis to derive a prediction equation for $\mathrm{DL}_{\mathrm{CO}}$ no significant interactions between standing height, sitting height, sex, and weight as independent variables were found. Although visual examination of Figure 2 might suggest that the slope for boys was significantly greater than the slope for girls, the interaction term (sex $\times$ height) was not statistically significant. Variables were added to the multiple regression equation until the $\mathrm{Cp}$ statistic suggested by Mallows ${ }^{17}$ was approximately equal to five, showing a satisfactory 

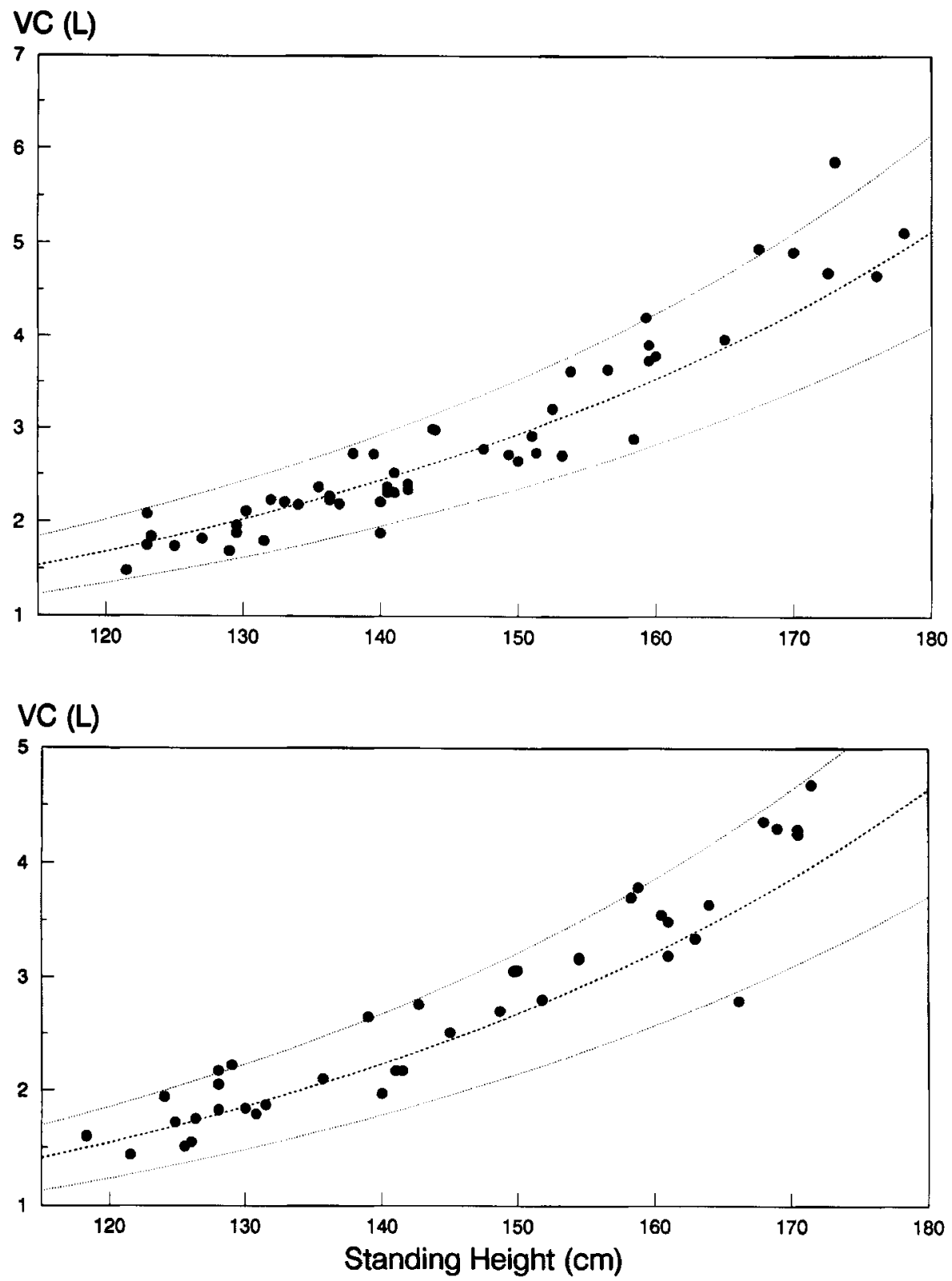

Fig. 1. Forced vital capacity in relation to standing height in our sample of $\mathbf{5 2}$ boys (above) and 40 girls (below). The lines correspond to the predicted means reported by Cotes $^{2}$ and the $95 \%$ confidence intervals.

fit. Table 3 shows the results with standing height, and Table 4 shows the results using sitting height. The latter could replace standing height in the equation but was not significant $(\mathrm{F}=0.173$, degrees of freedom $=1.87, P>$ $0.5)$ when standing height was in the equation. The final models show that in addition to stature, age, sex, and weight were significant variables, and that they add to the accuracy of the predictive equations which can be calculated from the data presented (Tables 3 and 4).

It is recommended by the American Thoracic Society that inspiratory volume for $\mathrm{DL}_{\mathrm{CO}}$ should exceed $90 \%$ of slow vital capacity in adults. In our study 46 children (50.5\%) did not meet this criterion. When the standard was set at $80 \%, 74$ children $(80 \%)$ met the criterion. Analysis of variance was performed using the model described above, and introducing the ratio of inspiratory volume to slow vital capacity as a covariate. The analysis showed that this ratio was not a significant covariate $(\mathrm{F}=1.323, \mathrm{DF}=1.87, P>0.05)$. When the presence or absence of a satisfactory ratio was used to select cases, whether the desired ratio was $90 \%$ or $80 \%$, the total explained variance remained constant, suggesting that a 
TABLE 2-Correlation Coefficients for DLco and Krogh Factor (DLco/TLC) in Relationship to Standing Height, Sitting Height, Age, and TLC for 92 Healthy Children

\begin{tabular}{lcccr}
\hline & $\begin{array}{c}\text { Standing } \\
\text { height }\end{array}$ & $\begin{array}{l}\text { Sitting } \\
\text { height }\end{array}$ & Age & \multicolumn{1}{c}{ TLC } \\
\hline DLco & $0.897^{* *}$ & $0.872^{* *}$ & $0.861^{*}$ & $0.926^{*}$ \\
Krogh Factor & -0.075 & -0.096 & -0.014 & $-0.314^{*}$ \\
Standing height & - & $0.972^{* *}$ & $0.922^{* *}$ & $0.887^{* *}$ \\
Sitting height & - & - & $0.891^{* *}$ & $0.872^{* *}$ \\
Age & - & - & - & $0.827^{* *}$ \\
\hline *ne-tailed $P<0.01$. & & & & \\
$* *$ One-tailed $P<0.001$. & & & &
\end{tabular}

ratio of inspiratory volume to slow vital capacity of $80 \%$ might be satisfactory in children.

\section{DISCUSSION}

This study was conducted to examine the relationship between standing and sitting heights, weight, age, sex, and lung diffusing capacity in normal children, tested with the single breath carbon monoxide diffusion method. Analysis of variance, using the multiple regression technique, showed that standing height, weight, age, and sex are significant predictors of $\mathrm{DL}_{\mathrm{CO}}$. Adding sitting height to the analysis did not significantly reduce the variation around the regression line, when standing height was in the equation. However, sitting height would substitute for standing height as it appeared to contain much of the same information. Predictive equations were calculated using sitting height as well as standing height, because there are clinical situations when it is not possible to measure standing height due to physical handicap.
Cotes et al. ${ }^{4}$ measured $\mathrm{DL}_{\mathrm{CO}}$ by the single breath method using a Resparameter in 212 healthy British twin children aged 8 to 16 years. The values of $\mathrm{DL}_{\mathrm{CO}}$ in relationship to TLC, to standing height, and to sitting height were $10-15 \%$ smaller than our values. ${ }^{4}$ Zapletal et al. ${ }^{1}$ measured $\mathrm{DL}_{\mathrm{CO}}$ by the single breath method with the Resparameter $\mathrm{Mk}_{4}$ (Morgan Ltd.) in 56 healthy children, 5 to 17 years old. Their measured values of $\mathrm{DL}_{\mathrm{CO}}$ in relationship to TLC were similar to our results. DeMuth and Howatt ${ }^{5}$ measured $\mathrm{DL}_{\mathrm{CO}}$ in 139 healthy 4 to 18 years old children by the rebreathing method. The reported values of $\mathrm{DL}_{\mathrm{CO}}$ in relationship to standing height were similar to ours. Strang ${ }^{7}$ measured $\mathrm{DL}_{\mathrm{CO}}$ in 79 subjects (44 boys and 35 girls) 5-14 years of age, using the steady state technique, and reported values that were 15-20\% smaller than ours. Bucci et al. ${ }^{3}$ measured DL ${ }_{\mathrm{CO}}$ in 597 to 40 year old subjects ( 43 were between 7 and 18 years of age), by the single breath carbon monoxide method of Krogh as adopted by Forster and co-workers. ${ }^{14}$ Their results for the 7-10 years old subjects were $20-25 \%$ higher than in our study; however, the results were

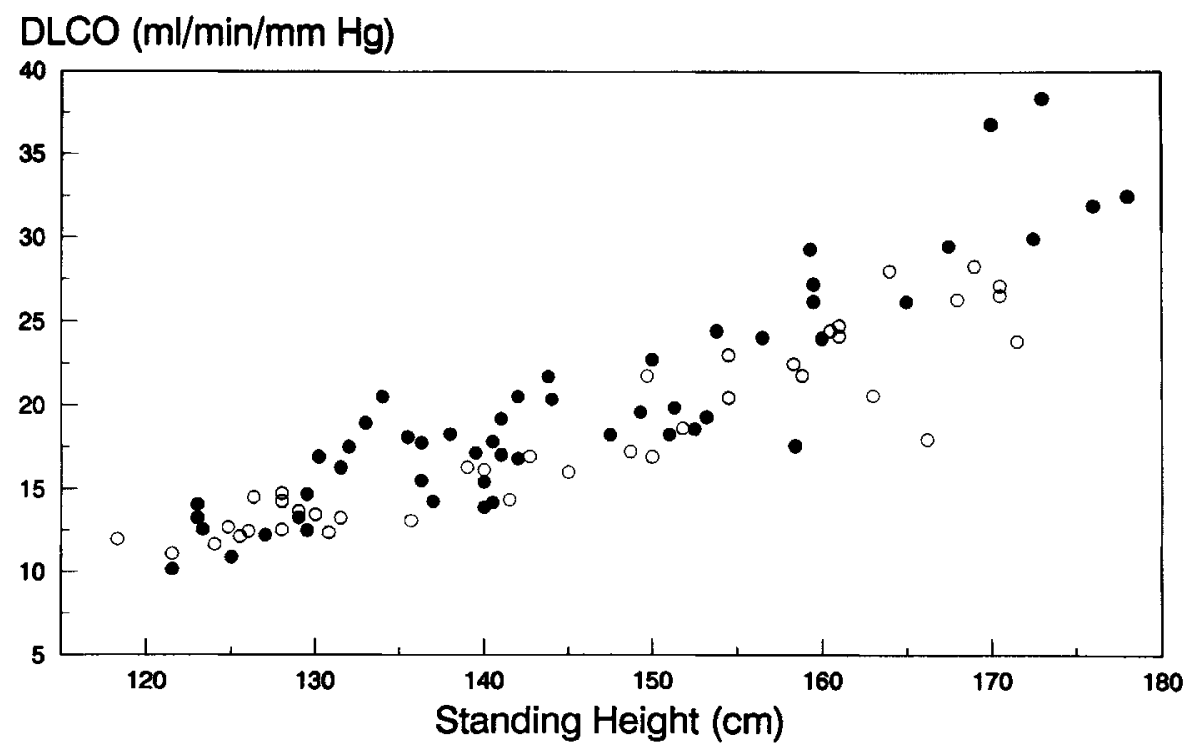

Fig. 2. $\mathrm{DL}_{\mathrm{co}}$ in relation to standing height in $\mathbf{5 2}$ normal boys (solid circles), and $\mathbf{4 0}$ normal girls (open circles). 
TABLE 3-Multiple Regression Equations for Prediction of DLco in 92 Healthy Children Using Standing Height, Sex ${ }^{a}$, Weight, and Age

\begin{tabular}{|c|c|c|c|c|c|c|}
\hline & $\begin{array}{c}\text { Regressor } \\
\text { variables }\end{array}$ & $\begin{array}{c}\text { Coefficient } \\
\text { estimate }\end{array}$ & $\begin{array}{l}\text { Standard } \\
\text { error of } \\
\text { coefficient } \\
\text { estimate }\end{array}$ & $\mathrm{Cp}$ & T-value & $P$-value \\
\hline I & $\begin{array}{l}\text { Constant } \\
\text { Standing height }(\mathrm{cm})\end{array}$ & $\begin{array}{r}-30.90 \\
0.3449\end{array}$ & $\begin{array}{l}2.6202 \\
0.0179\end{array}$ & $\begin{array}{c}26.4 \\
-\end{array}$ & $\begin{array}{r}-11.794 \\
19.258\end{array}$ & $\begin{array}{l}<0.001 \\
<0.001\end{array}$ \\
\hline II & $\begin{array}{l}\text { Constant } \\
\text { Standing height }(\mathrm{cm}) \\
\text { Sex }\end{array}$ & $\begin{array}{r}-28.09 \\
0.3441 \\
-1.8811\end{array}$ & $\begin{array}{l}2.6041 \\
0.0169 \\
0.5440\end{array}$ & $\begin{array}{c}14.8 \\
- \\
-\end{array}$ & $\begin{array}{r}-10.787 \\
20.349 \\
-\quad 3.458\end{array}$ & $\begin{array}{l}<0.001 \\
<0.001 \\
<0.001\end{array}$ \\
\hline III & $\begin{array}{l}\text { Constant } \\
\text { Standing height }(\mathrm{cm}) \\
\text { Sex } \\
\text { Weight }(\mathrm{kg})\end{array}$ & $\begin{array}{r}-19.46 \\
0.2610 \\
-\quad 2.0962 \\
0.0894\end{array}$ & $\begin{array}{l}4.1142 \\
0.0353 \\
0.5326 \\
0.0337\end{array}$ & $\begin{array}{l}9.4 \\
- \\
- \\
-\end{array}$ & $\begin{array}{r}-4.729 \\
7.386 \\
-3.936 \\
2.655\end{array}$ & $\begin{array}{l}<0.001 \\
<0.001 \\
<0.001 \\
<0.010\end{array}$ \\
\hline IV & $\begin{array}{l}\text { Constant } \\
\text { Standing height }(\mathrm{cm}) \\
\text { Sex } \\
\text { Weight }(\mathrm{kg}) \\
\text { Age }(\mathrm{yr})\end{array}$ & $\begin{array}{r}-11.64 \\
0.1655 \\
-2.2367 \\
0.0885 \\
0.5626\end{array}$ & $\begin{array}{l}5.0476 \\
0.0510 \\
0.5199 \\
0.0327 \\
0.2222\end{array}$ & $\begin{array}{l}5.0 \\
- \\
- \\
-\end{array}$ & $\begin{array}{r}2.305 \\
3.248 \\
-4.302 \\
2.708 \\
2.533\end{array}$ & $\begin{array}{l}<0.050 \\
<0.001 \\
<0.001 \\
<0.010 \\
<0.050\end{array}$ \\
\hline
\end{tabular}

a Where male $=1$ and female $=2$.

The variables are listed in the order in which they were entered into the stepwise regression equation.

TABLE 4-Multiple Regression Equations for Prediction of DLco in 92 Healthy Children Using Sitting Height, Sex ${ }^{a}$, Weight, and Age

\begin{tabular}{|c|c|c|c|c|c|c|}
\hline & $\begin{array}{c}\text { Regressor } \\
\text { variables }\end{array}$ & $\begin{array}{c}\text { Coefficient } \\
\text { estimate }\end{array}$ & $\begin{array}{c}\text { Standard } \\
\text { error of } \\
\text { coefficient } \\
\text { estimate } \\
\end{array}$ & $\mathrm{Cp}$ & $\mathrm{T}$-value & $P$-value \\
\hline 1 & $\begin{array}{l}\text { Constant } \\
\text { Sitting height }(\mathrm{cm})\end{array}$ & $\begin{array}{r}-34.94 \\
0.7093\end{array}$ & $\begin{array}{l}3.2227 \\
0.0420\end{array}$ & $\begin{array}{c}46.5 \\
-\end{array}$ & $\begin{array}{r}-10.840 \\
16.898\end{array}$ & $\begin{array}{l}<0.001 \\
<0.001\end{array}$ \\
\hline II & $\begin{array}{l}\text { Constant } \\
\text { Sitting height }(\mathrm{cm}) \\
\text { Age }(\mathrm{yr})\end{array}$ & $\begin{array}{r}-21.78 \\
0.4128 \\
0.8475\end{array}$ & $\begin{array}{l}4.5360 \\
0.0861 \\
0.2192\end{array}$ & $\begin{array}{c}29.2 \\
- \\
-\end{array}$ & $\begin{array}{r}-4.801 \\
4.797 \\
3.866\end{array}$ & $\begin{array}{l}<0.001 \\
<0.001 \\
<0.001\end{array}$ \\
\hline III & $\begin{array}{l}\text { Constant } \\
\text { Sitting height }(\mathrm{cm}) \\
\text { Age (yr) } \\
\text { Sex }\end{array}$ & $\begin{array}{r}-18.20 \\
0.4044 \\
0.8783 \\
-2.2806\end{array}$ & $\begin{array}{l}4.2542 \\
0.0791 \\
0.2015 \\
0.5460\end{array}$ & $\frac{12.1}{-}$ & $\begin{array}{r}-4.279 \\
5.112 \\
4.358 \\
-4.177\end{array}$ & $\begin{array}{l}<0.001 \\
<0.001 \\
<0.001 \\
<0.001\end{array}$ \\
\hline IV & $\begin{array}{l}\text { Constant } \\
\text { Sitting height }(\mathrm{cm}) \\
\text { Age (yr) } \\
\text { Sex } \\
\text { Weight }(\mathrm{kg})\end{array}$ & $\begin{array}{r}-8.50 \\
0.2377 \\
0.7883 \\
-2.4286 \\
0.1010\end{array}$ & $\begin{array}{l}5.1825 \\
0.0936 \\
0.1951 \\
0.5247 \\
0.0334\end{array}$ & $\begin{array}{l}5.0 \\
- \\
- \\
-\end{array}$ & $\begin{array}{r}-1.641 \\
2.538 \\
4.041 \\
-4.629 \\
3.024\end{array}$ & $\begin{array}{l}>0.050 \\
<0.050 \\
<0.001 \\
<0.001 \\
<0.010\end{array}$ \\
\hline
\end{tabular}

a Where male $=1$ and female $=2$.

The variables are listed in the order in which they were entered into the stepwise regression equation.

similar to ours in older children. We are unable to account for these differences with regard to different reports, because they were performed by different techniques and on different equipment. In addition, all sample sizes have been rather small, and few studies have presented data to show that their subjects are representative of a normal population.

Hemoglobin measurements were not made in our study because we did not have approval for venipuncture in normal children from our institutional review board. The subjects were healthy, and the medical history and physical examination did not reveal any unidentified medical conditions. Therefore, it is unlikely that the hemoglobin concentration was abnormal in any subject. In a diseased population, we recommend that hemoglobin should be measured and a correction for anemia applied to the measured $\mathrm{DL}_{\mathrm{CO}}$ value. ${ }^{18}$

In accordance with some earlier studies, ${ }^{5}$ we found no relationship between the Krogh factor $\left(\mathrm{DL}_{\mathrm{CO}} / \mathrm{TLC}\right.$ or $\mathrm{KCO}$ ) and standing or sitting height. These results do not support the findings of Cotes or of Zapletal et al. who reported that the Krogh factor decreases in relationship to 
growth in childhood. ${ }^{4,1}$ However, there was a relationship between Krogh factor and TLC $(P<0.01)$ in girls, which supports the earlier findings. It is possible that the discrepant results between different studies are due to sampling error, especially as the regression coefficient of $\mathrm{DL}_{\mathrm{CO}} / \mathrm{TLC}$ in relation to body height was small $(\mathrm{r}=$ -0.28 ) in the study by Zapletal et al. ${ }^{1}$ In that study, ${ }^{1}$ the membrane component $\left(\mathrm{D}_{\mathrm{m}}\right)$ and the alveolar capillary volume $\left(\mathrm{V}_{\mathrm{c}}\right)$ were also determined. It was shown that the reduction in the Krogh factor in relation to body height was the result of a reduction in alveolar capillary volume. There was no change in the membrane component with growth.

Analysis of the size of the inspiratory volume (IV) showed that there was no significant relationship between $\mathrm{DL}_{\mathrm{CO}}$ and the ratio of inspiratory volume to slow vital capacity (IV/SVC). The results suggest that a value of IV/SVC greater than $80 \%$ would be adequate for measurement of $\mathrm{DL}_{\mathrm{CO}}$ in children, although a value of $90 \%$ would be preferable in cooperative subjects.

Our data indicate that as children grow in height and weight from early childhood to young adulthood, the diffusing capacity of the pulmonary membrane correspondingly increases. We report multiple regression equations for calculating predicted $\mathrm{DL}_{\mathrm{CO}}$ values for children from height, gender, age, and weight. These values can be used as standards for the early detection and quantitation of interstitial lung disease and other restrictive pulmonary diseases.

\section{ACKNOWLEDGMENTS}

We thank Julie Nutting, R.R.T., for technical assistance, and Debra White for typing the manuscript. For reviewing the manuscript we thank William Eschenbacher, M.D., Peggy Harper, R.R.T. at the University of Michigan, and Michael Snow, R.P.F.T., Terry Kapsen, and Richard Beauchamp at Medical Graphics. Bonny Specker at the University of Cincinnati College of Medicine provided statistical advice.

\section{REFERENCES}

1. Zapletal A, Samánek M, Paul T. Lung function in children and adolescents, methods, reference values. Karger, 1987; 22:83112.
2. Cotes JE. Lung Function, Assessment, and Application in Medicine, 4th Ed. England: Blackwell Scientific Publications, 1979.

3. Bucci G, Cook CP, Barrie H. Studies of respiratory physiology in children, Part V. Total lung diffusion, diffusing capacity of pulmonary membrane, and pulmonary capillary blood volume in normal subjects from 7 to 40 years of age. J Pediatr. 1961; 58:820-828.

4. Cotes JE, Dabbs JM, Hall AM, Axford AT, Laurence K. Lung volumes, ventilatory capacity, and transfer factor in healthy British boy and girl twins. Thorax. 1973; 28:709-715.

5. DeMuth GR, Howatt WF. The growth of lung function; pulmonary diffusion. Pediatrics. 1965; 35: Supp. III:185-193.

6. Giammona ST, Daly WJ. Pulmonary diffusing capacity in normal children, ages 4 to 13. Am J Dis Ch. 1965; 110:144-152.

7. Strang LB. Measurements of pulmonary diffusing capacity in children. Arch Dis Ch. 1960; 35:232-235.

8. Miller A, Thornton JC, Warshaw R, Anderson H, Teirstein AS, Selikoff IJ. Single-breath diffusing capacity in a representative sample of the population of Michigan, a large industrial state. Predicted values, lower limits of normal and frequencies of abnormality by smoking history. Amer Rev Respir Dis. 1983; $127: 270-277$

9. Evaluation of impairment/disability secondary to respiratory disease: A statement of the American Thoracic Society. Amer Rev Respir Dis. 1982; 126:945-951.

10. Evaluation of impairment/disability sccondary to respiratory disorders: A statement of the American Thoracic Society. Amer Rev Respir Dis. 1986; 133:1205-1209.

11. Weng TR, Levison $\mathbf{H}$. Standards of pulmonary function in children. Amer Rev Respir Dis. 1969; 99:879-894.

12. Knudson RJ, Slatin RC, Lebowitz MD, et al. The maximal expiratory flow-volume curve: Normal standards, variability, and effects of age. Amer Rev Respir Dis. 1976; 113:587-600.

13. Krogh $\mathbf{M}$. The diffusion of gases through the lungs of man. $J$ Physiol. 1915; 49:271-300.

14. Forster RE, Crohn JE, Briscoe WA, Blackemere WS, Riley RL. A modification of the Krogh carbon monoxide breath holding technique for estimating the diffusing capacity of the lung: A comparison with three other methods. J Clin Invest. 1955; 34:1417-1426.

15. Ogilvie CM, Forster RE, Blakemere WS, Morton JW. A standardized breath holding technique for the clinical measurement of the diffusing capacity of the lung for carbon monoxide. J Clin Invest. 1957; 36:1-17.

16. Hamill PVV, Drizd TA, Johnson CL, Reed RB, Roche AF, Moore, WM. Physical growth: National Center for Health Statistics percentiles. Amer J Clin Nutr. 1979; 32:607-629.

17. Mallows CL. Some comments on Cp. Technometrics. 1973; 15:661-675.

18. Cotes JE, Dabbs JM, Elwood PC, Hall AM, McDonald A, Saunders, MJ. Iron deficiency anemia: Its effect on transfer factor for the lung (diffusing capacity) and ventilation and cardiac frequency during sub-maximal exercise. Clin Science 1972; 42:325-335 